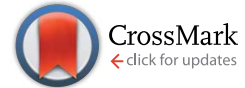

Cite this: RSC Adv., 2015, 5, 33681

Received 11th February 2015 Accepted 2nd April 2015

DOI: $10.1039 / c 5 r a 02665 b$

www.rsc.org/advances

\section{Surface-modified spherical activated carbon materials for pre-combustion carbon dioxide capture}

\author{
Nannan Sun, ${ }^{\text {ac }}$ Chenggong Sun, ${ }^{* a}$ Jingjing Liu, ${ }^{a}$ Hao Liu, ${ }^{\text {a }}$ Colin E. Snape, ${ }^{a}$ Kaixi Li, ${ }^{b}$ \\ Wei Wei ${ }^{c}$ and Yuhan Sun ${ }^{c}$
}

Surface modification of activated carbon beads via $\mathrm{HNO}_{3}$ oxidation and subsequent amination at elevated temperatures was investigated as a means to improve their performance for $\mathrm{CO}_{2}$ capture, and the effects of the resultant changes in porosity and surface chemistry on adsorption characteristics of the samples were studied. Characterisations conducted with elemental analysis, physical adsorption, X-ray photoelectron spectroscopy and scanning electron microscope demonstrate that both the porosity and surface chemistry of the carbon beads were tuned by the modification without any alteration of the integrity of the desirable spherical morphology. Adsorption evaluation with both thermogravimetric analysis and high pressure volumetric analysis under various conditions indicate that one of the modified samples had a high $\mathrm{CO}_{2}$ adsorption capacity $\left(8.64 \mathrm{mmol} \mathrm{g}^{-1}\right.$ at 20 bar and $30{ }^{\circ} \mathrm{C}$ ) with fast adsorption/desorption kinetics, superior durability and good selectivity over $\mathrm{N}_{2}$ and $\mathrm{H}_{2}$. Both the unique spherical form (diameter $=1.2 \pm 0.2 \mathrm{~mm}$ ) and the superior adsorption performance render the modified carbon beads a promising candidate for $\mathrm{CO}_{2}$ capture especially in pre-combustion capture using pressure swing adsorption.

\section{Introduction}

Various world energy outlooks suggest that in spite of the great efforts and heavy investments that have been made to improve energy efficiency and increase the share of renewable energy in primary energy supply, fossil fuels will continue to dominate the world primary energy supply for the coming decades. ${ }^{\mathbf{1 - 4}}$ Consequently, significant contributions from carbon capture and storage (CCS) will be required to combat climate change to increase the opportunity for the continual use of fossil fuels. ${ }^{5-7}$ However, the current state-of-the-art aqueous amine scrubbing technology for $\mathrm{CO}_{2}$ capture is prohibitive for wide deployment due to its high operational costs and high energy penalty associated with absorbent regeneration. ${ }^{\mathbf{8 9}}$ On the other hand, solid adsorbents looping technology (SALT) offers a viable alternative that has many advantages over solution-based technologies, including substantially reduced energy consumption, greatly minimised health, safety and environmental hazards and greater structural variability of the adsorbents that can be selected.

${ }^{a}$ Faculty of Engineering, University of Nottingham, University Park, Nottingham NG7 2RD, UK. E-mail: cheng-gong.sun@nottingham.ac.uk; Liu.Hao@nottingham.ac.uk

${ }^{b}$ Key Laboratory of Carbon Materials, Institute of Coal Chemistry, Chinese Academy of Sciences, Taiyuan 030001, PR China

${ }^{c}$ CAS Key Lab of Low-Carbon Conversion Science and Engineering, Shanghai Advanced Research Institute, Chinese Academy of Sciences, Shanghai 201203, PR China
Over recent years, a wide array of solid adsorbents have been used for $\mathrm{CO}_{2}$ capture, those including zeolites, carbon materials, inorganic oxides, amine modified silicates and more recently, the more niche metal-organic frameworks (MOFs) and covalent organic frameworks (COFs) materials. ${ }^{10-12}$ In previous investigations, a high adsorption capacity is the most pursued parameter among many others. ${ }^{\mathbf{1 0 , 1 1}}$ In practical carbon capture applications however, the so-called "working capacity" should be more important as it concerns both material and engineering issues. Other challenges facing real carbon capture applications, such as the large volume of flue gas at high flow rate, complicated chemical compositions of the flue gas and fast capture rate that is required, should also be emphasized. ${ }^{13}$ Therefore, one needs to consider process costs, process efficiencies and engineering feasibilities for a real carbon capture process, and these criteria impose further requirements for applicable $\mathrm{CO}_{2}$ adsorbents as illustrated in Fig. 1. For example, the factor of adsorption/desorption kinetics (factor 6 in Fig. 1) is located on the left-bottom of the triangle in Fig. 1 because adsorbents with fast kinetics can increase the efficiencies of a capturing process and lowering related costs by accelerating the adsorption/desorption cycles for a given carbon capture facility. Meanwhile, faster cycling requires a better designed and integrated adsorption/desorption subunit, giving rise to further challenges in process engineering and limitations in adsorbents selection. The comprehensive requirements for $\mathrm{CO}_{2}$ adsorbents are also discussed in a recent review by Sayari et al. ${ }^{\mathbf{1 4}}$ 




Fig. 1 Features of solid $\mathrm{CO}_{2}$ adsorbents for industrial applications.

A screening of the possible adsorbents for $\mathrm{CO}_{2}$ capture indicates that carbon based adsorbents represent a good option to balance all the factors in Fig. 1 due to its promising properties such as low cost for preparation, chemical inertness, easyto-regeneration, etc. ${ }^{10,11,14,15}$ As a result, the development of effective carbon-based adsorbent materials for $\mathrm{CO}_{2}$ capture has received significant attentions over recent years, ${ }^{15}$ related works including: (i) preparation of carbons by templating methods ${ }^{16,17}$ or direct carbonization of coal, ${ }^{18}$ polymers ${ }^{19,20}$ and biomass residuals; ${ }^{21-25}$ (ii) chemical activation of carbon by $\mathrm{KOH}^{21}$ and $\mathrm{K}_{2} \mathrm{CO}_{3} ;{ }^{22,26}$ and (iii) modification of carbon by $\mathrm{N}$ doping, ${ }^{17,20,27} \mathrm{~S}$ doping $^{28}$ and amine loading. ${ }^{29,30}$ More recently, some carbon materials with exceptionally high $\mathrm{CO}_{2}$ uptake were reported. For example, Srinivas et al. $^{31}$ prepared MOF-derived porous carbons with $\mathrm{CO}_{2}$ adsorption capacities as high as $27.0 \mathrm{mmol} \mathrm{g}^{-1}$ at $27^{\circ} \mathrm{C}$ and 30 bar. By carbonation and activation of selected coal tar pitches, a $\mathrm{CO}_{2}$ uptake of $20.5 \mathrm{mmol} \mathrm{g}^{-1}$ was obtained by Shao et al. at $25{ }^{\circ} \mathrm{C}$ and 18 bar. ${ }^{23}$ In addition to these results, Sjostrom et al..$^{32}$ has reached the conclusion that carbon can be the viable adsorbents for practical $\mathrm{CO}_{2}$ capture especially if their $\mathrm{CO}_{2}$ uptake can be improved, which emphasized again that carbon-based materials have great potential in $\mathrm{CO}_{2}$ capture, particularly for pre-combustion capture where the $\mathrm{CO}_{2}$ partial pressure in the gas stream is much higher than in postcombustion flue gases.

Although many carbon-based adsorbents currently under development have superior adsorption capacity, they are produced predominantly in low-density powder form which is unsuitable for practical applications and therefore needs to be further fabricated via pelletisation or granulation process with the aid of binders or additives, which can often lead to significant loss of their adsorption performance. ${ }^{33-38}$ To address this issue, some researchers tried to prepare carbon monolith/ honeycomb adsorbents using purpose-designed molding processes, ${ }^{20,39,40}$ however these methodologies often involves the use of complicated processes, and the fabricated materials, mostly in their cylindrical and/or rod shapes, are not particularly suitable for use in SALT processes (e.g. circulating fluidized bed) due to serious attrition problems that may arise from the undesirable material morphology.

In our previous work, a cost-effective and easy-to-scale-up hydrothermal technique has successfully been developed to produce spherical active carbon materials from a variety of polymeric precursors. The prepared porous carbon beads possess the most favourable properties for applications in continuous $\mathrm{CO}_{2}$ capture using circulating fluidised bed, such as their tuned porosity, high mechanical strength and desirable spherical forms with uniform diameters. ${ }^{41}$ In this paper, different post-treatments, including $\mathrm{HNO}_{3}$ oxidation and amination were investigated as an effective means to further improve the $\mathrm{CO}_{2}$ adsorption performance of the carbon beads, the adsorption behaviour of the samples was rationalized based on extensive characterization tests, and their application potential in $\mathrm{CO}_{2}$ capture was evaluated based on the analysis of adsorption capacity, selectivity, kinetics and reusability.

\section{Experimental}

\subsection{Preparation of the original carbon beads}

The parent carbon beads were prepared from phenolic resins using a novel hydrothermal process. Typically, novolac-type phenolic resins were first dissolved in a formulated solvent to form a solution which was later mixed with aqueous polyvinyl alcohol (PVA) and sealed in an autoclave. The mixture was then heated to $130{ }^{\circ} \mathrm{C}$ at a rate of $5{ }^{\circ} \mathrm{C} \mathrm{min}{ }^{-1}$ and held at this temperature for $1 \mathrm{~h}$ with rigorous stirring (400 rpm). The autoclave reactor was then cooled down to ambient temperature to allow the formed resin beads to be recovered. The resin beads was first washed adequately with distilled water and dried at $110^{\circ} \mathrm{C}$ for $24 \mathrm{~h}$ before it was carbonised in $\mathrm{N}_{2}$ at $800^{\circ} \mathrm{C}$ for $1 \mathrm{~h}$ to yield the carbon beads (sample $A C$, hereafter) for further treatments.

\subsection{Surface modification of sample $A C$}

The $A C$ sample was further submitted to $\mathrm{HNO}_{3}$ oxidation by mixing $10 \mathrm{~g}$ of $A C$ and $250 \mathrm{~mL}$ of concentrated $\mathrm{HNO}_{3}$ in a beaker at room temperature $\left(25^{\circ} \mathrm{C}\right)$ for $1 \mathrm{~h}$ (sample oxAC), after washing and drying, the obtained $o x A C$ was aminated in a tube furnace under $\mathrm{NH}_{3}$ at 300,600 and $800{ }^{\circ} \mathrm{C}$ to afford sample oxAC-300NH3, oxAC-600NH3 and oxAC-800NH3, respectively. For comparison, a sample thermally treated at $800^{\circ} \mathrm{C}$ in $\mathrm{N}_{2}$ after $\mathrm{HNO}_{3}$ oxidation was also prepared (oxAC-800N2).

\subsection{Characterization}

Textural properties of the samples were measured by $\mathrm{N}_{2}$ physisorption on an Micromeritics ASAP 2420 instrument at $-196{ }^{\circ} \mathrm{C}$ and $\mathrm{CO}_{2}$ at $0{ }^{\circ} \mathrm{C}$. Prior to any measurements, all samples were first degassed at $120{ }^{\circ} \mathrm{C}$ overnight. The apparent surface area $\left(S_{\mathrm{BET}}\right)$ was calculated according to the method suggested by Parra et $a .^{42}$ The cumulative pore volumes $\left(V_{\text {total }}\right)$ were calculated from the amount of nitrogen adsorbed at $P / P_{0}$ of $c a .0 .99$, and the average pore diameter $\left(D_{\text {avg }}\right)$ was calculated by $4 V_{\text {total }} /$ $\mathrm{SA}_{\mathrm{BET}}$. The micropore volume $\left(V_{\text {micro }}\right)$ and surface area $\left(\mathrm{SA}_{\text {micro }}\right)$ 
were determined by the $t$-plot method. Narrow micropore volumes $\left(W_{0}\right)$ of the samples were calculated by the DubininRadushkevich (DR) method ${ }^{\mathbf{4 3}}$ from $\mathrm{CO}_{2}$ isotherms obtained at $0{ }^{\circ} \mathrm{C}$. In theory, the DR method allows the calculation of average width of the narrow micropores $\left(L_{0}\right)$ based on the empirical relationship between $L_{0}$ and the characteristic adsorption potential $\left(E_{0}\right)$ in the DR equation. ${ }^{44}$ However, it was reported that this relationship is influenced by the surface chemistry of samples. ${ }^{45}$ Therefore, $L_{0}$ was not calculated here due to the significant differences in the surface properties of the samples.

X-Ray photoelectron spectroscopy (XPS) was carried out using a Kratos AXIS ULTRA instrument with an $\mathrm{Al} \mathrm{K \alpha}$ source (energy $1486.6 \mathrm{eV}$ ). The high resolution scans were charge corrected to the main C1s peak $(284.8 \mathrm{eV})$. Morphology of the samples was examined with a QUANTA 600 scanning electron microscope (SEM) instrument. An elemental analyser (Thermo EA1112 series) was used to determine the carbon, hydrogen, and nitrogen contents of the samples.

\subsection{Evaluation of the $\mathrm{CO}_{2}$ adsorption performance}

The $\mathrm{CO}_{2}$ capture behaviors of the samples were measured by a TA Q500 thermal gravimetric analyser (TGA) under ambient pressure. In brief, $20-30 \mathrm{mg}$ of the samples were loaded in a platinum pan, heated to $115^{\circ} \mathrm{C}$ and held at this temperature in flowing $\mathrm{N}_{2}\left(100 \mathrm{~mL} \mathrm{~min}^{-1}\right)$ for $10 \mathrm{~min}$ to remove any physisorbed moisture and/or $\mathrm{CO}_{2}$, and the temperature was then decreased $\left(10{ }^{\circ} \mathrm{C} \mathrm{min}^{-1}\right)$ to and equilibrated at $30{ }^{\circ} \mathrm{C}$. To start the adsorption tests, the gas flow was switched to $100 \mathrm{~mL} \mathrm{~min}^{-1}$ of pure $\mathrm{CO}_{2}$ or 15 vol\% $\mathrm{CO}_{2}$ in $\mathrm{N}_{2}$ to perform $\mathrm{CO}_{2}$ adsorption tests and the temperature was held at $30{ }^{\circ} \mathrm{C}$ for $30 \mathrm{~min}$ in order for the adsorption to reach equilibrium. The samples were then heated to $115{ }^{\circ} \mathrm{C}$ at a ramp rate of $0.5{ }^{\circ} \mathrm{C} \mathrm{min}^{-1}$. The use of such a slow ramp allows the adsorption to change with temperature in a quasi-equilibrium state and the mass change recorded can be used to assess the influence of temperature on $\mathrm{CO}_{2}$ adsorption capacity. Reversibility of $\mathrm{CO}_{2}$ adsorption/desorption was previously checked to make sure the as-obtained data is valid.

High pressure $\mathrm{CO}_{2}$ adsorption tests were carried out with a High Pressure Volumetric Analyser (Particulate Systems HPVA100). Prior to any tests, the sample was first degassed in vacuum at $120{ }^{\circ} \mathrm{C}$ overnight to remove any physisorbed moisture and/or $\mathrm{CO}_{2}$.

\section{Results and discussion}

\subsection{Characterization}

3.1.1 Elemental analysis. Table 1 presents the results from elemental analysis (EA) of the samples. The parent $A C$ showed a high carbon content of $93.6 \mathrm{wt} \%$. This result is expectable as the sample was derived from phenolic resin precursors containing little mineral substances. After $\mathrm{HNO}_{3}$ treatment (sample oxAC), the contents of oxygen and nitrogen increased by an order of magnitude due to the introduction of surface nitrogen and oxygen-bearing functionalities, such as hydroxyl, carboxyl and quinine groups. ${ }^{46}$ Significant proportions of these functionalities were eliminated during the subsequent thermal treatment in $\mathrm{N}_{2}$ as indicated by the decreased oxygen and nitrogen contents in the sample oxAC-800N2. Similarly, both the nitrogen and oxygen contents diminished when $o x A C$ was treated by $\mathrm{NH}_{3}$ at 300 and $600{ }^{\circ} \mathrm{C}$, which is a typical behaviour for the pyrolysis of carbon precursors. ${ }^{26}$ Interestingly, although the $o x A C$ sample showed the highest bulk nitrogen content, the highest surface nitrogen content was observed for the sample oxAC-300NH3 as measured by XPS. This result confirms the occurrence of surface reactions between $\mathrm{NH}_{3}$ and oxygenated groups to introduce nitrogen functionalities onto the surface of oxAC-300NH3. Despite the decrease in surface nitrogen concentration observed for $o x A C-600 \mathrm{NH} 3$, further increase of the amination temperature to $800{ }^{\circ} \mathrm{C}$ led to the increase of nitrogen content in the resulted $o x A C-800 \mathrm{NH} 3$, indicating a different mechanism of nitrogen incorporation process at different temperatures that might lead to the formation of different nitrogen-bearing functionalities. It is believed that at high temperatures such as $800{ }^{\circ} \mathrm{C}$, most of the oxygenated groups have decomposed, and therefore the surface amination was mainly dominated by the anchoring of free radicals such as $\mathrm{NH}_{2}$ and $\mathrm{NH}$ from the decomposition of $\mathrm{NH}_{3}$, and the formed nitrogen functionalities had a higher opportunity to further cleavage the $\mathrm{N}-\mathrm{H}$ bond, leading to the formation of pyridine-like structures. This assumption is also in line with decreased $\mathrm{H} / \mathrm{N}$ mass ratio with the increasing of amination temperature (Table 1).

3.1.2 Textural properties. Fig. 2 and Table 2 summarise the textural properties of the samples measured by the physical adsorption of $\mathrm{N}_{2}$ at $-196{ }^{\circ} \mathrm{C}$ and $\mathrm{CO}_{2}$ at $0{ }^{\circ} \mathrm{C}$. According to the IUPAC classification, all but the oxAC sample exhibited a type-I isotherm, suggesting the materials are mainly microporous. ${ }^{47}$

Table 1 Weight based composition measured by EA and XPS (dry base)

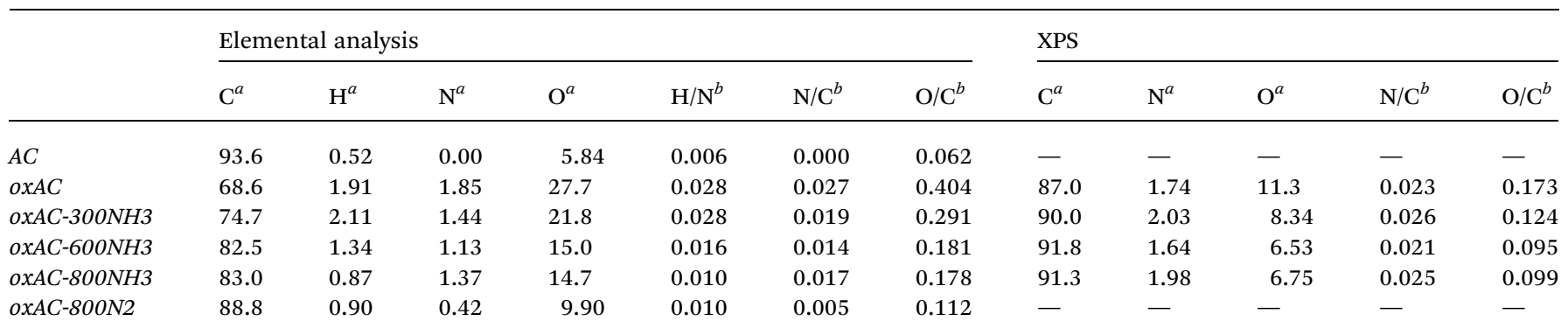

${ }^{a}$ Weight percentage in $\mathrm{wt} \% .{ }^{b}$ Mass ratio, a.u. 


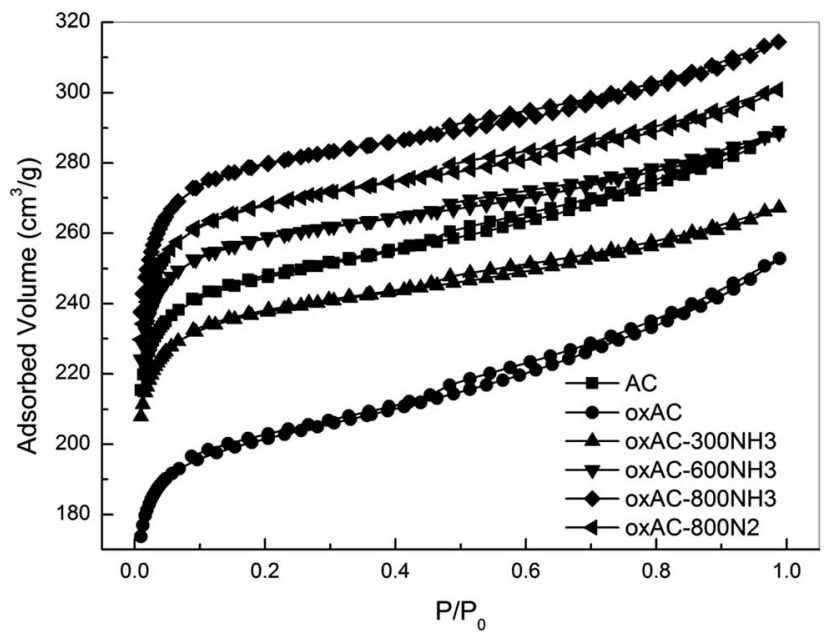

Fig. $2 \mathrm{~N}_{2}$ isotherms of the samples.

The isotherm of $o x A C$ is characterized by an opening knee and a considerable increase of $\mathrm{N}_{2}$ uptake at higher partial pressure region, indicating its higher fraction of mesopores.

As shown in Table 2, the parent carbon beads (sample $A C$ ) have a moderate surface area $\left(\mathrm{SA}_{\mathrm{BET}}\right)$ of $972 \mathrm{~m}^{2} \mathrm{~g}^{-1}$ with a total pore volume $\left(V_{\text {total }}\right)$ of $0.45 \mathrm{~cm}^{3} \mathrm{~g}^{-1}$. After $\mathrm{HNO}_{3}$ oxidation, the $\mathrm{SA}_{\mathrm{BET}}$ and $V_{\text {total }}$ of $o x A C$ decreased with slightly increased average pore diameter $\left(D_{\mathrm{avg}}\right)$. Upon removal of the generated oxygen-containing groups by thermal treatment in $\mathrm{N}_{2}$, a significant improvement in porosity can be observed for oxAC$800 N 2$, which has a surface area comparable to that of the parent sample $A C$. It has been frequently reported that $\mathrm{HNO}_{3}$ oxidation can reduce the porosity of carbon materials, ${ }^{47,48}$ due to either the blockage of micropores by the formed oxygencontaining functionalities or partial destruction of the carbon framework by damaging the basal planes. ${ }^{49}$ Although pore blockage cannot be ruled out based on the present data, the high microporosity of the oxAC-800N2 convinced us that extra micropores, which could be recovered by the removal of oxygencontaining functionalities during thermal treatment, were formed via the penetration of the carbon framework by the oxidant. As shown in Table 2, both oxAC and oxAC-800N2 exhibit $W_{0}$ values similar to that of the parent sample $A C$ of $c a$. $0.24 \mathrm{~cm}^{3} \mathrm{~g}^{-1}$, suggesting that the influence of $\mathrm{HNO}_{3}$ treatment on the narrow micropores is small. This can be expected, given the difficulty for the oxidant to enter these narrow micropores as a result of the high surface tension of the aqueous solution and the hydrophobic nature of the carbon surface.

A substantial increase in microporosity was observed for the $300{ }^{\circ} \mathrm{C}$ aminated sample (oxAC-300NH3). It is interesting to note that while the total micropore volume of the oxAC3OONH3 increased by over $20 \%$ as compared with oxAC (from 0.28 to $\left.0.35 \mathrm{~cm}^{3} \mathrm{~g}^{-1}\right)$, the total pore volume of this sample remained relatively unchanged ( 0.41 versus $\left.0.39 \mathrm{~cm}^{3} \mathrm{~g}^{-1}\right)$. This implies that the mesopores in the sample $o x A C$ diminished due to pore narrowing during the amination, which might be trigged by the reactions of $\mathrm{NH}_{3}$ with the oxygenate groups. ${ }^{50-52}$ Similar assumption can be applied to explain the increase of $W_{0}$ for this sample because carbon activation by $\mathrm{NH}_{3}$ becomes less effective under temperatures as low as $300{ }^{\circ} \mathrm{C}$. With increasing the amination temperature from 300 to $800{ }^{\circ} \mathrm{C}$, further activation/ surface modification of the carbon beads can be achieved, which imposed a range of changes on the porosity of the samples such as formation of new narrow-micropores, widening/blocking of the existing wide- and narrowmicropores, etc. ${ }^{\mathbf{1 8 , 2 7}}$ These synergetic effects led to a gradual increase in $S_{\text {micro }} / V_{\text {micro }}$ and a decrease in $W_{0}$. Consequently, both the $\mathrm{SA}_{\mathrm{BET}}$ and $V_{\text {total }}$ increased for the oxAC-600NH3 and oxAC-800NH3 samples. It seems that the increase was most likely induced by the enhancement of wide-microporosity as indicated by the similar increasing of $V_{\text {total }}$ and $V_{\text {micro }}$. Similar results, namely the increased wide-microporosity during enhanced activation, were also observed by An et al. during their attempts to carbonise activated carbon fibre-phenolic resin composites. ${ }^{39}$

3.1.3 Morphology. Morphology of the samples observed by SEM are presented in Fig. 3. In general, surface modification imposed little influence on the morphological integrity of the desired spherical form, and all the samples showed similar morphology (details not shown). It has been reported this kind of spherical materials possess great potential and engineering flexibilities in large scale process as their shape and texture exhibit the ability to minimize material attrition in circulating fluidized bed reactors. ${ }^{53}$ Interconnected 3D porous network structures are also evident inside the carbon beads with irregular openings and cracks in $\mu \mathrm{m}$-scale on both the external and internal surfaces of the samples (Fig. $3 \mathrm{a}$ and b). These features serve as channels for fluids to pass through and thus facilitate

Table 2 Textural properties of the samples

\begin{tabular}{|c|c|c|c|c|c|c|}
\hline & \multirow[b]{2}{*}{$\mathrm{SA}_{\mathrm{BET}}\left(\mathrm{m}^{2} \mathrm{~g}^{-1}\right)$} & \multirow[b]{2}{*}{$V_{\text {total }}\left(\mathrm{cm}^{3} \mathrm{~g}^{-1}\right)$} & \multirow[b]{2}{*}{$D_{\text {avg }}(\mathrm{nm})$} & \multicolumn{3}{|l|}{ Microporosity } \\
\hline & & & & $\mathrm{SA}_{\text {micro }}{ }^{a}\left(\mathrm{~m}^{2} \mathrm{~g}^{-1}\right)$ & $V_{\text {micro }}{ }^{a}\left(\mathrm{~cm}^{3} \mathrm{~g}^{-1}\right)$ & $W_{0}^{b}\left(\mathrm{~cm}^{3} \mathrm{~g}^{-1}\right)$ \\
\hline$A C$ & 972 & 0.45 & 1.84 & 907 & 0.36 & 0.238 \\
\hline oxAC & 788 & 0.39 & 1.99 & 707 & 0.28 & 0.245 \\
\hline oxAC-300NH3 & 936 & 0.41 & 1.77 & 891 & 0.35 & 0.277 \\
\hline oxAC-600NH3 & 1020 & 0.45 & 1.75 & 974 & 0.38 & 0.262 \\
\hline oxAC-80ONH3 & 1106 & 0.49 & 1.76 & 1052 & 0.41 & 0.237 \\
\hline oxAC-800N2 & 1058 & 0.47 & 1.76 & 1009 & 0.40 & 0.247 \\
\hline
\end{tabular}

${ }^{a}$ Calculated by $t$-plot method. ${ }^{b}$ Calculated from $\mathrm{CO}_{2}$ adsorption at $0{ }^{\circ} \mathrm{C}$ by applying DR method. 


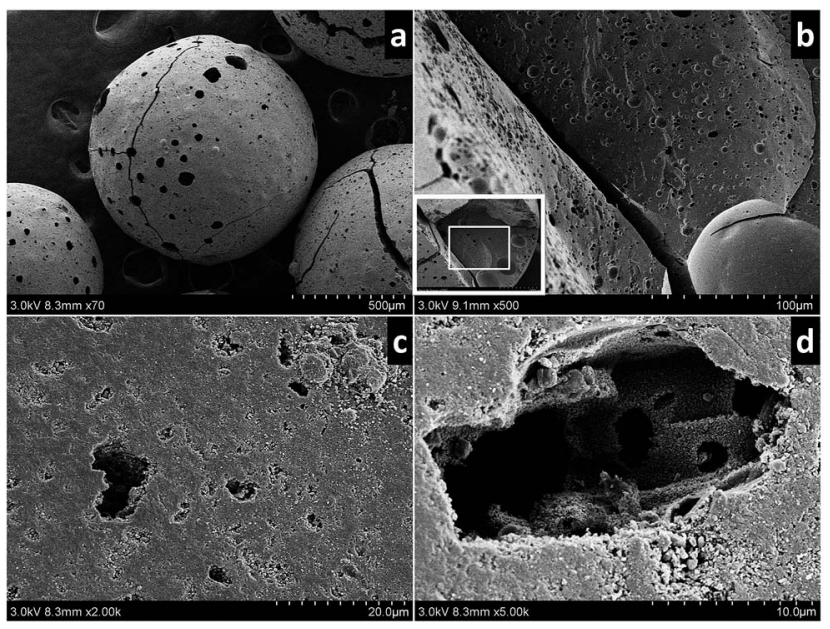

Fig. 3 SEM images of the samples (a) an oxAC bead, (b) cracks and pores inside an oxAC bead (c) smooth outer surface of $A C$, (d) initial particles and pores inside an $A C$ bead.

the more effective diffusion of $\mathrm{CO}_{2}$ molecules within the interior porous networks present in the carbon beads, which is of vital importance for the adsorption efficiency and kinetics of the materials. ${ }^{22} \mathrm{~A}$ closer check of the carbon beads revealed a relatively smooth outer surface (Fig. 3c), indicating a better capability for these samples to resist attrition. In contrast, as showed in Fig. 3d, the surface of cavities inside the carbon beads are sponge-like frameworks comprising of relatively uniform microspheres with a diameter of $c a .100 \mathrm{~nm}$.

3.1.4 Surface chemistry. It has been recognized that the $\mathrm{CO}_{2}$ affinity of $\mathrm{N}$ functionalities incorporated into graphene structures were governed by the mobility and delocalization of the lone pair electrons on the $\mathrm{N}$ atoms, which is determined by adjacent chemical environment. ${ }^{54}$ Therefore, XPS was carried out over the oxidized and aminated samples to investigate their surface chemistries. The quantified surface compositions are listed in Table 1. For clearer comparison with the EA results, the initially obtained atomic compositions were converted to weight-percentage concentrations. As can be seen, increases in nitrogen and oxygen contents were evident as a result of $\mathrm{HNO}_{3}$ oxidation, being consistent with the EA results. Substantially higher surface N/C mass ratios measured by XPS were found for all aminated samples, while the values obtained for oxAC from EA and XPS were similar. On the other hand, it is interesting to note that all the $\mathrm{O} / \mathrm{C}$ mass ratios measured by XPS were considerably lower than those measured by EA, being in contrast to the trend observed for the N/C mass ratios. This clearly indicates again that the oxidation by liquid phase $\mathrm{HNO}_{3}$ was so aggressive that not only the surface, but also the carbon framework was altered by involving nitrogen and oxygen atoms. The hypothesis can be evidenced by the considerably higher $\mathrm{O} / \mathrm{C}$ mass ratios measured by EA than that by XPS, which is indicative of the preferential occurrence of oxygenated functionalities within the carbon framework in addition to the outmost surface. As mentioned in Section 3.1.2, due to the hydrophobic nature of the $A C$ surface, it is reasonable to assume that during oxidation, the distribution of aqueous $\mathrm{HNO}_{3}$ over the carbon surface is unlikely to be uniform but preferably in the form of micro droplets. This might lead to the localised penetration of the corrosive $\mathrm{HNO}_{3}$ into the carbon framework, creating interior "channels" with abundance of oxygenate groups. By comparing the textural parameters of oxAC and oxAC-800N2 (Table 2), it can be concluded that these "channels" can be regarded as blocked micropores where oxygen present in various functionalities that can hardly be detected by XPS. In contrast, there is little limitation on the accessibility of the $\mathrm{NH}_{3}$ molecule to enter the micropores, and thus amination occurs more evenly and preferably on the surface, leading to pore widening and surface enrichment of nitrogen as revealed by the higher N/C ratio measure by XPS than that of EA.

Fig. 4 presents the N1s spectra and the peak fitting results of the N-containing samples, for the sample oxAC, peaks at 399.4, 401.0 , and $406.0 \mathrm{eV}$ can be attributed to pyridinic, quaternary and nitro-nitrogen according to the NIST XPS Database. After amination, a new peak was detected at $400.0 \mathrm{eV}$, which is attributable to pyrrolic and/or pyridone nitrogen. Although these two functionalities cannot be effectively differentiated by XPS, it was reported that pyridone nitrogen is more stable than pyrrolic nitrogen at elevated temperatures, ${ }^{55}$ therefore pyridone has a higher opportunity to survive on the aminated samples. Among the identified groups, pyridinic nitrogen has lone pair of electrons, which may enhance the alkaline character of the surface, and thus would facilitate the adsorption of acidic $\mathrm{CO}_{2}$. As for the pyridone nitrogen, Fan et al. has reported that the p- $\pi$ conjugation between the $-\mathrm{OH}$ and the aromatic rings endows the ortho-N with a higher electron density, which can lead to higher affinity for $\mathrm{CO}_{2}$ adsorption. ${ }^{26}$ It is noteworthy that the delocalization and conjugation effects from electrons of nitrogen, aromatic rings and other atoms have a significant impact on the basicity of nitrogen-containing groups, therefore it is arbitrary to allege the relative importance of these groups in terms of their affinity to acid gases such as $\mathrm{CO}_{2} \cdot{ }^{56,57}$ For the quaternary and nitro-nitrogen on the other hand, they are

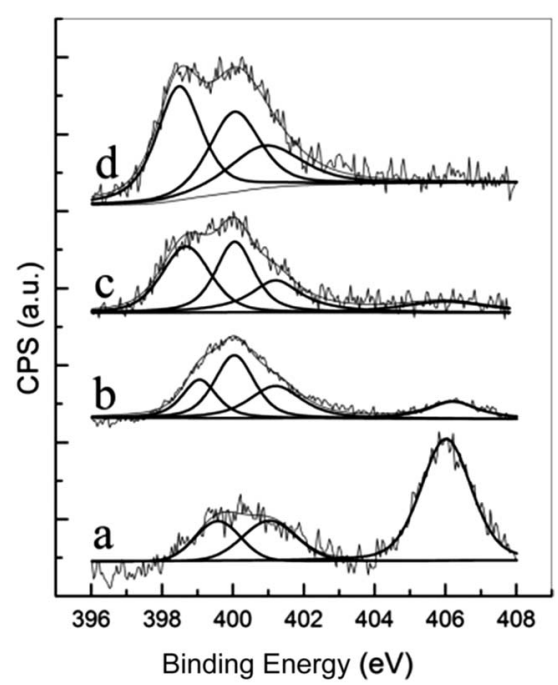

Fig. 4 XPS spectra of the oxidized and aminated samples (a) oxAC, (b) oxAC-300NH3, (c) oxAC-600NH3, (d) oxAC-800NH3. 
Table 3 Assignment and fraction of surface $\mathrm{N}$ functionalities

\begin{tabular}{lllll}
\hline & \multicolumn{2}{l}{ Fractions (\%) } & \\
\cline { 2 - 5 } Samples & Pyridine & Pyridone & Quaternary & $-\mathrm{NO}_{2}$ \\
\hline oxAC & 16.4 & - & 20.4 & 63.2 \\
oxAC-300NH3 & 20.8 & 37.0 & 27.1 & 15.1 \\
oxAC-600NH3 & 33.8 & 31.0 & 22.4 & 12.9 \\
oxAC-800NH3 & 42.5 & 32.4 & 25.1 & -
\end{tabular}

partially positive charged due to the adjacent oxygen and aromatic rings, therefore it is reasonable to assume a limited contribution for these functionalities to the adsorption of $\mathrm{CO}_{2}$.

The relative fractions of the identified nitrogen functionalities are tabulated in Table 3 . It can be observed that with the increase of amination temperature, the fraction of nitronitrogen decreased notably due to the removal and/or reduction of these functionalities, while the relative abundance of pyridone and quaternary nitrogen were less affected due to their higher thermal stability as compared with nitro-nitrogens. A higher fraction of pyridinic nitrogen can be seen for the samples aminated at higher temperatures, which is indicative of the enhanced surface amination by the formed N-radicals and further cleavage of the $\mathrm{N}-\mathrm{H}$ bonds at higher temperatures as has been discussed in Section 3.1.1.

\section{2 $\mathrm{CO}_{2}$ adsorption behaviour}

3.2.1 Adsorption capacity. The spherical carbon adsorbents, including both the parent and surface-modified carbon beads, were subjected to different test regimes to determine their performance for $\mathrm{CO}_{2}$ capture. Table 4 presents the $\mathrm{CO}_{2}$ uptakes of the samples measured in TGA at different $\mathrm{CO}_{2}$ partial pressures, and significant improvements in $\mathrm{CO}_{2}$ adsorption capacity was obtained for the surface-modified carbon beads particularly at low $\mathrm{CO}_{2}$ partial pressures. At $30{ }^{\circ} \mathrm{C}$ and ${\mathrm{a} \mathrm{CO}_{2}}$ partial pressure of 0.15 bar, the oxAC sample, which has the lowest textural properties (Table 2), shows the highest $\mathrm{CO}_{2}$ uptake $\left(0.91 \mathrm{mmol} \mathrm{g}^{-1}, 25 \%\right.$ increase as compared with $\left.A C\right)$. This can be ascribed to the strong affinity of the abundant heteroatom functionalities, oxygenate functional groups in particular, with the quadrupole moment of the $\mathrm{CO}_{2}$ molecule.

Table $4 \quad \mathrm{CO}_{2}$ adsorption capacities of the samples at different partial pressures under atmospheric conditions

\begin{tabular}{llllll}
\hline & \multicolumn{2}{l}{$\begin{array}{l}15 \mathrm{vol} \% \mathrm{CO}_{2} \\
(\mathrm{mmol} \mathrm{g})\end{array}$} & & & \multicolumn{2}{l}{$\begin{array}{l}100 \mathrm{vol} \% \mathrm{CO}_{2} \\
\left(\mathrm{mmol} \mathrm{g}^{-1}\right)\end{array}$} \\
\cline { 2 - 3 } \cline { 5 - 6 } Sample & $30{ }^{\circ} \mathrm{C}$ & $45{ }^{\circ} \mathrm{C}$ & & $30{ }^{\circ} \mathrm{C}$ & $45{ }^{\circ} \mathrm{C}$ \\
\hline AC & 0.73 & 0.48 & & 2.36 & 1.71 \\
oxAC & 0.91 & 0.59 & & 2.34 & 1.72 \\
oxAC-300NH3 & 0.85 & 0.56 & & 2.57 & 1.90 \\
oxAC-600NH3 & 0.76 & 0.50 & & 2.44 & 1.78 \\
oxAC-800NH3 & 0.74 & 0.49 & & 2.42 & 1.75 \\
oxAC-800N2 & 0.73 & 0.48 & & 2.39 & 1.74
\end{tabular}

Similar effects have also been reported for carbons, MOFs and task-specific ionic liquids (TSILs). ${ }^{\mathbf{2 8 , 5 8 , 5 9}}$ When comparing adsorption capacity at $15 \mathrm{vol} \% \mathrm{CO}_{2}$ of the three aminated smaples, it can be observed that oxAC-300NH3 possessed the highest $\mathrm{CO}_{2}$ uptake at both 30 and $45{ }^{\circ} \mathrm{C}$, which can be explained by the higher amount of $\mathrm{N}-\mathrm{H}$ functionalities (Tables 1 and 3) because the binding between $\mathrm{CO}_{2}$ and $\mathrm{C}-\mathrm{N}-\mathrm{H}$ groups is stronger than that of $\mathrm{C}=\mathrm{N}-\mathrm{C}$. At a $\mathrm{CO}_{2}$ partial pressure of 1 bar, the $\mathrm{CO}_{2}$ uptake of all the aminated samples were higher than that of $o x A C$, suggesting the greater importance of textural properties on adsorption capacity. The sample oxAC-300NH3 showed the highest uptake $\left(2.57 \mathrm{mmol} \mathrm{g}^{-1}\right)$, most probably due to its highest narrow micropore volume $\left(W_{0}\right)$. It has been reported that at atmospheric pressure, only pores with diameters lower than 5 times of the molecular size of the adsorbate are effective for gas adsorption. ${ }^{18}$ As for $\mathrm{CO}_{2}$, the dynamic molecular diameter is $0.209 \mathrm{~nm}$, it is therefore expected that the narrow micropores are the major locations that accommodate $\mathrm{CO}_{2}$ at 1 bar. ${ }^{39}$ The combinative effect of surface chemistry and textural properties on $\mathrm{CO}_{2}$ adsorption of surface-modified carbon materials has been well-demonstrated in open literatures, ${ }^{\mathbf{4 1 , 5 4}}$ and it is believed that the surface chemistry, rather than the textural properties, governs the $\mathrm{CO}_{2}$ capture performance at lower (partial) pressures, while the textural properties becomes more important at higher $\mathrm{CO}_{2}$ pressures as the adsorption process becomes controlled by the micropore filling mechanism.

In fact, activated carbons in general are well known for their capability to achieve higher adsorption capacities at pressures higher than atmospheric, and this together with their moderate adsorption strength makes them the ideal adsorbents for $\mathrm{CO}_{2}$ capture at high pressures (such as pre-combustion capture). ${ }^{21,23,31}$ In this study, the high pressure $\mathrm{CO}_{2}$ adsorption performance of the samples was measured using a high pressure volumetric method, and the obtained isotherms are presented in Fig. 5. Note that all the reported high pressure adsorption capacities are absolute loadings, calculated from the experimentally obtained excess loadings and $V_{\text {total }}$ by using Peng-Robinson equation of state as suggested by Myers and Wang. ${ }^{\mathbf{6 0 , 6 1}}$ For all the samples, $\mathrm{CO}_{2}$ uptake increased with the increasing of pressure, and the highest uptakes of 8.64 and $7.93 \mathrm{mmol} \mathrm{g}^{-1}$ were achieved over sample oxAC-800NH3 at 30 and $45{ }^{\circ} \mathrm{C}$, respectively. These high uptakes together with the unique spherical form and good mechanical strength make the current carbon beads a promising option for $\mathrm{CO}_{2}$ capture applications. Fig. 6 illustrates the adsorption capacities at a pressure of 20.2 bar as a function of the BET surface areas of the samples, and the obtained good linear relationship highlighted the vital importance of the above mentioned pore filling mechanism where textural properties are expected to be the key driver of $\mathrm{CO}_{2}$ uptake at elevated pressures.

Table 5 presented a comparison of the $\mathrm{CO}_{2}$ adsorption capacity of the carbon beads with those phenolic resin-derived carbons reported in the literature. It can be seen that the adsorption capacity of samples reported here is only slightly lower than those non-KOH activated carbon adsorbents in a powder form. Together with the uniform spherical form, we 



Fig. 5 High pressure $\mathrm{CO}_{2}$ adsorption isotherms of the samples (a) $30^{\circ} \mathrm{C}$, (b) $45^{\circ} \mathrm{C}$.



Fig. 6 Adsorption capacity at 20.2 bar as a function of BET surface area.

Table 5 A comparison on the $\mathrm{CO}_{2}$ adsorption capacity of the current study and reported values

\begin{tabular}{llll}
\hline Ref. & KOH activation & $\begin{array}{l}\text { Adsorption } \\
\text { temperature }\left({ }^{\circ} \mathrm{C}\right)\end{array}$ & $\begin{array}{l}\text { Adsorption } \\
\text { capacity }(w t \%)\end{array}$ \\
\hline 62 & No & 25 & 2.45 \\
41 & No & 30 & 2.34 \\
39 & No & 20 & 2.27 \\
63 & No & 25 & 3.30 \\
20 & No & 25 & 3.20 \\
64 & No & 25 & 2.75 \\
65 & No & 25 & 2.90 \\
66 & No & 25 & 2.75 \\
67 & Yes & 23 & 4.59 \\
21 & Yes & 25 & 4.41 \\
This work & No & 30 & 2.57 \\
& & &
\end{tabular}

thus believe these carbon beads may represent a potential option for practical $\mathrm{CO}_{2}$ capture. We are currently working on the effect of $\mathrm{KOH}$ activation on the adsorption performance as well as the morphological integrity of the carbon beads.

To examine the effectiveness of the carbon beads as an adsorbent for pre-combustion $\mathrm{CO}_{2}$ capture by pressure swing adsorption, the working capacity of the carbon adsorbents,
Table 6 Working capacities of the samples

\begin{tabular}{llc}
\hline & \multicolumn{2}{l}{ Working capacities $^{a}\left(\mathrm{mmol} \mathrm{g}^{-1}\right)$} \\
\cline { 2 - 3 } Sample & $30{ }^{\circ} \mathrm{C}$ & $45^{\circ} \mathrm{C}$ \\
\hline$A C$ & 4.01 & 4.21 \\
oxAC & 3.15 & 3.18 \\
oxAC-300NH3 & 3.67 & 3.77 \\
oxAC-600NH3 & 4.29 & 4.33 \\
oxAC-800NH3 & 4.81 & 4.94 \\
oxAC-800N2 & 4.46 & 4.54 \\
${ }^{a}$ Defined as the difference of equilibrium adsorption capacity at 20 and \\
2 bar.
\end{tabular}

which is defined as the difference in equilibrium capacities at given adsorption and desorption pressures (in the present case, 20 and 2 bar for adsorption and desorption, respectively), were obtained as shown in Table 6. Of all the samples examined, the sample $0 x A C-800 N H 3$ showed the highest working capacity of $4.94 \mathrm{mmol} \mathrm{g}^{-1}$, which is nearly $20 \%$ higher than that of the parent $A C$. It is also interesting to highlight that the working capacities of all the carbon beads at $45{ }^{\circ} \mathrm{C}$ are slightly higher than those achieved at $30{ }^{\circ} \mathrm{C}$, this is a phenomenon that has rarely been reported in previous studies on activated carbons, but is fairly meaningful because carbon-based materials are normally regarded as a highly temperature-sensitive adsorbents that rapidly lost their capacities with increasing temperatures, and thus the current observations are persuasive to demonstrate the feasibility of using the current carbon-based materials for pre-combustion $\mathrm{CO}_{2}$ capture by pressure swing adsorption.

3.2.2 Adsorption selectivity. To assess the selectivity of the carbon adsorbents for $\mathrm{CO}_{2}$ over $\mathrm{N}_{2}$ and $\mathrm{H}_{2}$, the $\mathrm{N}_{2}$ and $\mathrm{H}_{2}$ adsorption isotherms were measured and compared with those of $\mathrm{CO}_{2}$ for some of the modified samples, namely oxAC and $o x A C-300 N H 3$. It can be seen from Fig. 7 that within the adsorption pressure range examined, the adsorption capacities of the samples for $\mathrm{CO}_{2}$ are remarkably higher than those for both $\mathrm{N}_{2}$ and, in particular, $\mathrm{H}_{2}$. Here, the ratio of adsorption capacity of different gases under 5.0 bar was used as an indicator for the adsorption selectivity, the $\mathrm{CO}_{2} / \mathrm{N}_{2}$ selectivities thus obtained were 4.61 and 4.81 for $0 x A C$ and oxAC-300NH3, 

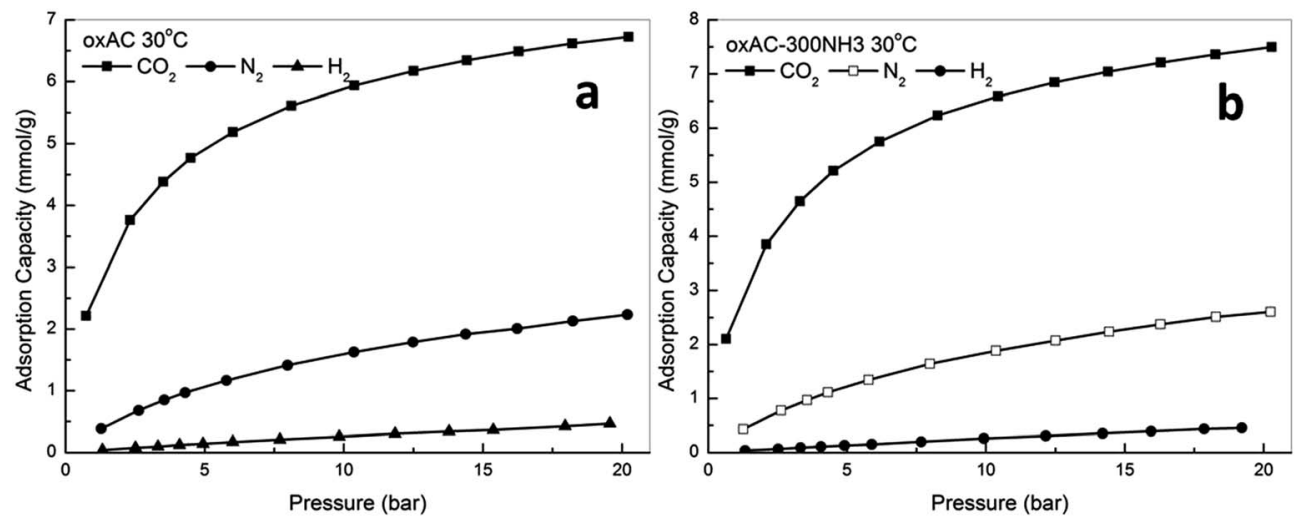

Fig. 7 Comparison of adsorption isotherms for $\mathrm{CO}_{2}, \mathrm{~N}_{2}$ and $\mathrm{H}_{2}$ (a) oxAC, (b) oxAC-300NH3.
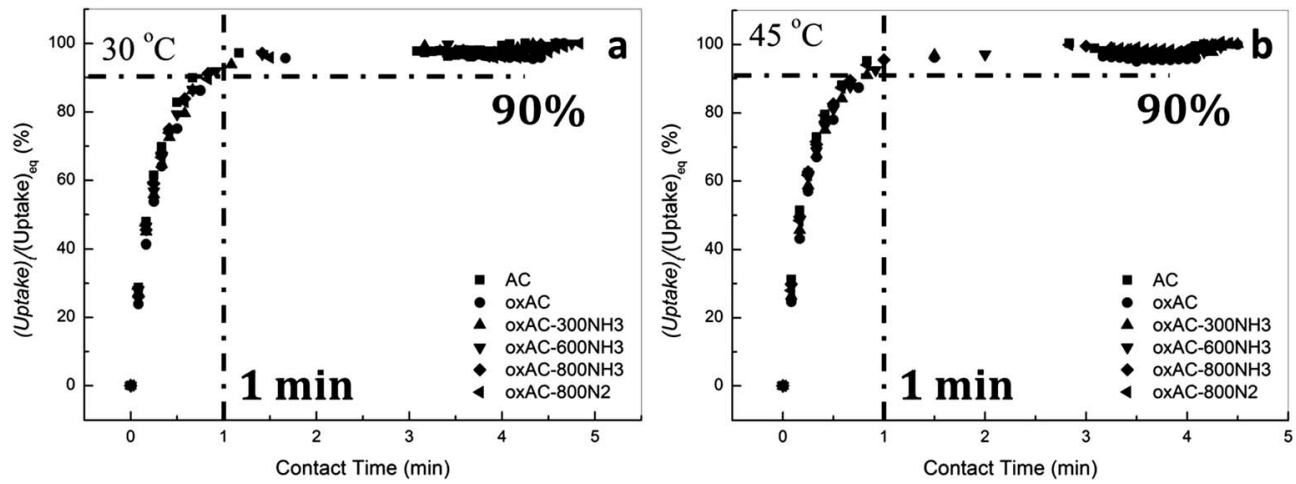

Fig. 8 Kinetics of high pressure (10 bar) $\mathrm{CO}_{2}$ adsorption (a) $30{ }^{\circ} \mathrm{C}$, (b) $45^{\circ} \mathrm{C}$.

respectively. There values are remarkably higher for $\mathrm{CO}_{2} / \mathrm{H}_{2}$ (30.50 and 38.36). Although investigations are ongoing, it is expected that the selectivity for $\mathrm{CO}_{2}$ can be even higher in a competitive adsorption process, given the higher surface affinity of the adsorbents to $\mathrm{CO}_{2}$ than to $\mathrm{N}_{2}$ and $\mathrm{H}_{2}$.

3.2.3 Adsorption kinetics. Using the $\mathrm{CO}_{2}$ adsorption data obtained from the high pressure volumetric adsorption analyser, the adsorption kinetics could be estimated by plotting the ratio of the $\mathrm{CO}_{2}$ uptake at time $t$ to the equilibrium uptake, (uptake) $t$ (uptake) $)_{\text {eq }}$, as a function of contact time $t$. The results are shown in Fig. 8. It is encouraging that regardless of the operation temperature, $90 \%$ of the equilibrium capacity could be achieved within less than $1 \mathrm{~min}$ and only approximately $2 \mathrm{~min}$ is needed to reach the full equilibrium capacity for all the samples, highlighting the desirable adsorption kinetics of the carbon beads for $\mathrm{CO}_{2}$ capture.

3.2.4 Cyclic adsorption performance. The reusability of oxAC-300NH3 was evaluated by TGA as presented in Fig. 8 . Within 20 cycles of adsorption and desorption, there are negligible changes on the $\mathrm{CO}_{2}$ uptake (Fig. 9a), an inspection of the weight change curve (Fig. 9b) indicates that the fast adsorption/desorption kinetics is stable as well, which is
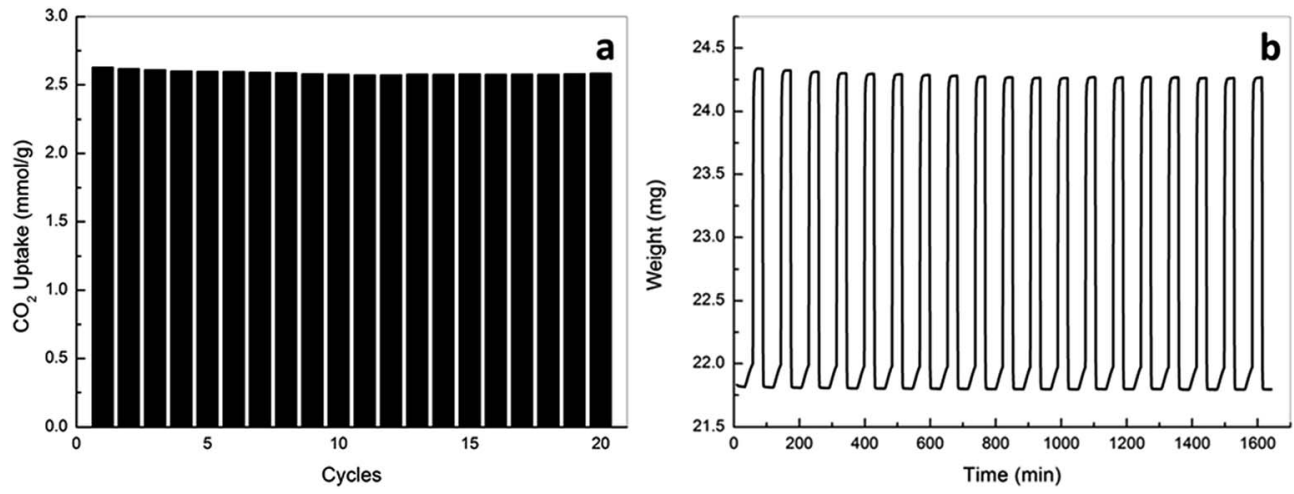

Fig. 9 Reusability of oxAC-300NH3 (a) $\mathrm{CO}_{2}$ uptake, (b) weight change curve. 
important to enhance the cyclic working capacity of the samples at reduced circulating times. The superior cyclic adsorption performance together with other adsorption characteristics as mentioned above endows the novel spherical carbon adsorbents with great promise in practical pre-combustion capture applications using pressure swing adsorption.

\section{Conclusion}

The effectiveness of using surface amination treatments as a means to improve the $\mathrm{CO}_{2}$ capture performance of carbon beads produced from a novel cost-effective hydrothermal process has been investigated. It was found that the surface modifications hardly compromised the desirable spherical morphology and mechanical strength of the activated carbon beads while their adsorption performance for $\mathrm{CO}_{2}$ was enhanced. In specific, $\mathrm{HNO}_{3}$ oxidation and low temperature amination with $\mathrm{NH}_{3}$ appear to be significantly more effective in improving the low pressure $\mathrm{CO}_{2}$ adsorption performance of the carbon beads, while the modification with $\mathrm{NH}_{3}$ at high temperatures was found instead to be more effective to boost their capture capacity at high pressures. Comprehensive characterisations demonstrate that the $\mathrm{CO}_{2}$ uptake capacity of the carbons at low $\mathrm{CO}_{2}$ partial pressures was more related to their surface chemistry and narrow micropores, while the high pressure adsorption capacity was found to have a linear relationship with the BET surface areas, indicating a pore-filling dominated adsorption mechanism. The highest working capacity of $c a$. $4.9 \mathrm{mmol} \mathrm{g}^{-1}$ was achieved for the sample oxAC-800NH3 and little variation was observed with the adsorption temperatures examined in this investigation. The results demonstrate the great potential of the spherical carbon beads as $\mathrm{CO}_{2}$ adsorbents particularly suitable for precombustion capture by pressure swing adsorption systems.

\section{Acknowledgements}

The authors wish to acknowledge the financial support of the UK EPSRC Grants (EP/I010955/1, EP/G063176/1), and the National Natural Science Foundation of China (51061130536, 51172251).

\section{References}

1 IEA, World energy outlook 2012, OECD/IEA, France, 2012.

2 IEA, World energy outlook 2013, OECD/IEA, France, 2013.

3 ExxonMobil, The outlook for energy: A view to 2040, USA, 2013. 4 BP, BP energy outlook 2013, UK, 2013.

5 Climate change, The scientific basis, Contribution of working group I to the third assessment report of the intergovernmental panel on climate change, Cambridge University Press, Cambridge (United Kingdom) and New York (NY, USA), 2001.

6 L. Christian, Science, 2010, 330, 595-596.

7 M. O. Franklin, Energy Environ. Sci., 2009, 2, 449-458.

8 T. R. Gary, Science, 2009, 325, 1652-1654.
9 M. E. Boot-Handford, J. C. Abanades, E. J. Anthony, M. J. Blunt, S. Brandani, N. Mac Dowell, J. R. Fernandez, M. C. Ferrari, R. Gross, J. P. Hallett, R. S. Haszeldine, P. Heptonstall, A. Lyngfelt, Z. Makuch, E. Mangano, R. T. J. Porter, M. Pourkashanian, G. T. Rochelle, N. Shah, J. G. Yao and P. S. Fennell, Energy Environ. Sci., 2014, 7, 130-189.

10 S. Choi, J. H. Drese and C. W. Jones, ChemSusChem, 2009, 2, 796-854.

11 Q. Wang, J. Luo, Z. Zhong and A. Borgna, Energy Environ. Sci., 2011, 4, 42-55.

12 S. Wang, S. Yan, X. Ma and J. Gong, Energy Environ. Sci., 2011, 4, 3805-3819.

13 P. Markewitz, W. Kuckshinrichs, W. Leitner, J. Linssen, P. Zapp, R. Bongartz, A. Schreiber and T. E. Mueller, Energy Environ. Sci., 2012, 5, 7281-7305.

14 A. Sayari, Y. Belmabkhout and R. Serna-Guerrero, Chem. Eng. J., 2011, 171, 760-774.

15 S. S. Mohammad, W. M. A. W. Daud, A. Houshmand and A. Shamiri, J. Anal. Appl. Pyrolysis, 2010, 89, 143-151.

16 S.-Y. Lee, D. Jang, S.-T. Bae and S.-J. Park, Int. J. Hydrogen Energy, 2014, 39, 12347-12352.

17 Y. Xia, R. Mokaya, G. S. Walker and Y. Zhu, Adv. Energy Mater., 2011, 1, 678-783.

18 M. M. Maroto-Valer, Z. Tang and Y. Zhang, Fuel Process. Technol., 2005, 86, 1487-1502.

19 J. Ludwinowicz and M. Jaroniec, Carbon, 2015, 82, 297-303.

20 G. P. Hao, C. W. Li, D. Qian and A. H. Lu, Adv. Mater., 2010, 22, 853-857.

21 L. K. C. De Souza, N. P. Wickramaratne, A. S. Ello, M. J. F. Costa, C. E. F. Da Costa and M. Jaroniec, Carbon, 2013, 65, 334-340.

22 T. C. Drage, A. Arenillas, K. M. Smith, C. Pevida, S. Piippo and C. E. Snape, Fuel, 2007, 86, 22-31.

23 X. Shao, Z. Feng, R. Xue, C. Ma, W. Wang, X. Peng and D. P. Cao, AIChE J., 2011, 57, 3042-3051.

24 G. K. Parshetti, S. Chowdhury and R. Balasubramanian, Fuel, 2015, 148, 246-254.

25 X. Zhang, S. Zhang, H. Yang, Y. Feng, Y. Chen, X. Wang and H. Chen, Chem. Eng. J., 2014, 257, 20-27.

26 X. Fan, L. Zhang, G. Zhang, Z. Shu and J. Shi, Carbon, 2013, 61, 423-430.

27 S. M. Mahurin, J. Górka, K. M. Nelson, R. T. Mayes and S. Dai, Carbon, 2014, 67, 457-464.

28 H. Seema, K. C. Kemp, N. H. Le, S. W. Park, V. Chandra, J. W. Lee and K. S. Kim, Carbon, 2014, 66, 320-326.

29 L. Zhao, Z. Bacsik, N. Hedin, W. Wei, Y. H. Sun, M. Antonietti and M. M. Titirici, ChemSusChem, 2010, 3, 840-845.

30 M. L. Gray, Y. Soong, K. J. Champagne, J. Baltrus, R. W. Stevens, P. Toochinda and S. S. C. Chuang, Sep. Purif. Technol., 2004, 35, 31-36.

31 G. Srinivas, V. Krungleviciute, Z. Guo and T. Yildirim, Energy Environ. Sci., 2014, 7, 335-342.

32 S. Sjostrom and H. Krutka, Fuel, 2010, 89, 1298-1306.

33 M. E. Davis, Nature, 2002, 417, 813-821. 
34 G. P. Hao, W. C. Li, D. Qian, G. H. Wang, W. P. Zhang, T. Zhang, A. Q. Wang, F. Schuth, H. J. Bongard and A. H. Lu, J. Am. Chem. Soc., 2011, 133, 11378-11388.

35 M. R. Lohe, M. Rose and S. Kaskel, Chem. Commun., 2009, 40, 6056-6058.

36 A. E. Kadib, R. Chimenton, A. Sachse, F. Fajula, A. Galarneau and B. Coq, Angew. Chem., Int. Ed., 2009, 48, 4969-4972.

37 J. L. Williams, Catal. Today, 2001, 69, 3-9.

38 J. J. Wen, F. N. Gu, F. Wei, Y. Zhou, W. G. Lin, J. Yang, J. Y. Yang, Y. Wang, Z. G. Zou and J. H. Zhu, J. Mater. Chem., 2010, 20, 2840-2846.

39 H. An, B. Feng and S. Su, Carbon, 2009, 47, 2396-2405.

40 Y. Jin, S. C. Hawkins, C. P. Huynh and S. Su, Energy Environ. Sci., 2013, 6, 2591-2596.

41 N. N. Sun, C. G. Sun, H. Liu, J. J. Liu, L. Stevens, T. Drage, C. E. Snape, K. X. Li, W. Wei and Y. H. Sun, Fuel, 2013, 113, 854-862.

42 J. B. Parra, J. C. Sousa, R. C. Bansal, J. J. Pis and J. A. Pajares, Adsorpt. Sci. Technol., 1995, 12, 51-66.

43 M. M. Dubinin, Chemistry and physics of carbon, Marcel Dekker Inc., USA, 1966.

44 F. Stoeckli and L. Ballerini, Fuel, 1991, 70, 557-559.

45 R. Ghosal and D. M. Smith, J. Porous Mater., 1996, 3, 247255.

46 J. W. Shim, S. J. Park and S. K. Ryu, Carbon, 2001, 39, 16351642.

47 K. S. W. Sing, D. H. Everett, R. A. W. Haul, L. Moscou, R. A. Pierotti, J. Rouquerol and T. Siemieniewska, Pure Appl. Chem., 1985, 57, 603-619.

48 P. Chingombe, B. Saha and R. J. Wakeman, Carbon, 2005, 43, 3132-3143.

49 P. Vinke, M. Van Der Eijk, M. Verbree, A. F. Voskamp and H. Van Bekkum, Carbon, 1994, 32, 675-686.

50 C. Pevida, M. G. Plaza, B. Arias, J. Fermoso, F. Rubiera and J. J. Pis, Appl. Surf. Sci., 2008, 254, 7165-7172.
51 B. Stöhr and H. P. Boehm, Carbon, 1991, 29, 707-720.

52 H. P. Boehm, G. Mair, T. Stoehr, A. R. De Rincon and B. Tereczki, Fuel, 1984, 63, 1061-1063.

53 S. Araki, H. Doi, Y. Sano, S. Tanaka and Y. Miyake, J. Colloid Interface Sci., 2009, 339, 382-389.

54 A. Arenillas, T. C. Drage, K. Smith and C. E. Snape, J. Anal. Appl. Pyrolysis, 2005, 74, 298-306.

55 A. W. Marek, J. R. Pels and J. A. Moulijn, Fuel, 1995, 74, 507516.

56 G. Sethia and A. Sayari, Energy Fuels, 2014, 28, 2727-2731.

57 A. Zukal, I. Dominguez, J. Mayerová and J. Čejka, Langmuir, 2009, 25, 10314-10321.

58 Z. Xiang, S. Leng and D. Cao, J. Phys. Chem. C, 2012, 116, 10573-10579.

59 F. Karadas, M. Atilhan and S. Aparicio, Energy Fuels, 2010, 24, 5817-5828.

60 A. L. Myers and P. A. Monson, Langmuir, 2002, 18, 1026110273.

61 J. Wang, A. Heerwig, M. R. Lohe, M. Oschatz, L. Borchardt and S. Kaskel, J. Mater. Chem., 2012, 22, 13911-13913.

62 C. F. Martin, M. G. Plaza, S. Garcia, J. J. Pis, F. Rubiera and C. Pevida, Fuel, 2011, 90, 2064-2072.

63 L. Liu, Q. F. Deng, T. Y. Ma, X. Z. Lin, X. X. Hou, Y. P. Liu and Z. Y. Yuan, J. Mater. Chem., 2011, 21, 16001-16009.

64 J. Choma, K. Jedynak, W. Fahrenholz, J. Ludwinowicz and M. Jaroniec, Appl. Surf. Sci., 2014, 289, 592-600.

65 M. G. Plaza, K. J. Thurecht, C. Pevida, F. Rubiera, J. J. Pis, C. E. Snape and T. C. Drage, Fuel Process. Technol., 2013, 110, 53-60.

66 J. Wei, D. Zhou, Z. Sun, Y. Deng, Y. Xia and D. Zhao, Adv. Funct. Mater., 2013, 23, 2322-2328.

67 N. P. Wickramaratne and M. Jaroniec, J. Mater. Chem. A, 2013, 1, 112-116. 